Fecha de recepción: diciembre 2010 Fecha de aceptación: julio 2011

Versión final: marzo 2012
Lenguaje, comunicación y Diseño

Verónica Devalle*

\begin{abstract}
Resumen: El artículo propone un recorrido histórico sobre la relación problemática entre diseño, comunicación y lenguaje. Se parte de la consideración sobre los lenguajes que hacen las vanguardias artístico-políticas de principios del siglo XX para acceder a una primera tensión moderna- entre lenguaje y comunicación. Por su parte, el análisis de lo desarrollado en Bauhaus permite comprender la relación entre comunicación y diseño. Luego de esta primera parte, el texto avanza hacia los problemas comunicacionales que se presentan en la inmediata posguerra y el modo en que el diseño comienza a asimilar concepciones provenientes de la teoría cibernética de la comunicación. En este punto, el artículo repasa los avances que en términos comunicacionales se han operado en las últimas décadas y que, en no pocas ocasiones, colisionan con el universo proyectual donde se ubica el diseño.
\end{abstract}

Palabras clave: comunicación - disciplina - Diseño - historia - lenguaje.

[Resúmenes en inglés y portugués en las páginas 253-254]

${ }^{(*)}$ Doctora en Teoría e Historia de las Artes (UBA). Licenciada en Sociología (UBA). Investigadora Adjunta del CONICET. Docente en la Universidad de Palermo y en la Universidad de Buenos Aires.

Escuela Superior de Diseño no es, por cierto, una traducción muy exacta de 'Hochschule für Gestaltung'. En los países de habla inglesa se dispone de la palabra 'design' para traducir no pocas de las acepciones posibles de la alemana 'Gestaltung': creación, formación, estructuración, trazado, delineación, dibujo, configuración, desarrollo, desenvolvimiento, realización, organización, aprovechamiento, confección (Wörterbuch der spanischen und deutschen Sprache, Rudolf J. Slaby y Rudolf Grossmann).

En español, por desgracia, carecemos de esta posibilidad. No obstante, a falta de otra mejor, la revista nv adoptará la palabra 'diseño', aunque dándole un nuevo sentido, precisamente el sentido de Gestaltung o design (Maldonado, 1955, p.7). 
Así comenzaba el artículo "La educación social del creador en la Escuela Superior de Diseño" de Tomás Maldonado, publicado en el número 7 de la revista nueva visión ( $n v)^{1}$ en el año 1955. La publicación constituye al día de hoy una referencia ineludible para el Diseño argentino y latinoamericano en la medida en que, tal como se trasluce en la cita, aparece por primera vez en el mundo hispano-parlante una nota sobre la creación de la mítica Hochschule für Gestaltung (HfG - Escuela de Diseño de la ciudad de Ulm, Alemania), escrita con un doble propósito; por un lado, dar cuenta de la importancia de la Escuela y el proyecto pedagógico que la sostenía, por el otro, de delimitar claramente el dominio del Diseño como disciplina académica y como saber técnico social.

Se comenzaba a delinear así el contorno de una definición disciplinaria a caballo entre el dominio de las formas, la creación, organización, racionalización y lo que Maldonado enuncia en su recurrente estilo proposicional, marca de agua de su escritura. Desde su perspectiva, no se trata de definir el propósito de la enseñanza del Design desde un posicionamiento meramente formal, sino que -y diferenciado claramente la HfG de Ulm de la Escuela de Chicago dirigida por Moholy-Nagy - la misma tenía que recuperar el contenido moral de la Modernidad, vacante desde ya en la Alemania post nazismo, es decir construir formas que merezcan ser creadas desde el punto de vista de la ética. El enemigo aquí era el styling-sinónimo del Diseño para las ventasy el modo en que lo moderno, en los EEUU en particular, se iba transformando en un estilo.

La escuela aparecía entonces como una suerte de sitio de resistencia cultural, a contrapelo de las tendencias propias del capitalismo industrialista impulsado en la posguerra y el despliegue indiscriminado de dispositivos de venta, que -para aquel entonces- comenzaban a entrever al Diseño como un claro factor de aumento del valor simbólico de las mercancías. Las formas creadas por el artista o el diseñador debían entonces ser moralmente legítimas, sanas y eficientes, recuperando no ya la utopía productivista (Maldonado, 1993, pp. 61-63), pero sí la línea conceptual del funcionalismo, la austeridad y despojamiento de las vanguardias constructivas y el ideario de una visión evolucionista del despliegue de lo humano. En este programa, el lenguaje cumplía un rol central.

Efectivamente, además de considerar que la producción debía centrarse en la cobertura de las necesidades humanas -en un claro guiño a los postulados de Bauhaus y la recuperación de su legado-impulsando una batalla ideológica contra lo que se consideraba producción de formasmercancía (claramente ejemplificado en el styling), el horizonte filosófico de esta reflexión se encontraba resueltamente identificado con humanismo propio de la segunda posguerra. Desde aquí, todas las intervenciones humanas en el mundo, y el Diseño dentro de ellas, debían detentar un fuerte compromiso ético -en el sentido de la responsabilidad en el hacer y en el decir. Por estas razones, la comunicación y su plataforma -el lenguaje- eran objeto de una profunda reflexión. La pregunta que seguía abierta era: ¿cómo había sido posible el genocidio nazi? ¿qué había sucedido?, al margen y más allá de preguntarse por quienes habían sido sus responsables. En el repertorio de las respuestas, una en particular se destacaba en aquellos momentos. La sospecha de la presencia de un fuerte componente ideológico en el lenguaje, en sus usos coloquiales y en sus formas más elaboradas de información, particularmente visibles en el rol jugado por la prensa y el periodismo. Informar, persuadir e instalar estigmatizaciones de las figuras sociales eran leídos como componentes de un mismo problema: aquel que había llevado a desconocer la condición humana de una gran parte de la humanidad y obrar en consecuencia. Dicho en otros términos, al reconocer el horror de haber instalado el racismo como un sentido común, 
la mirada interrogativa debía volver a los planos de la enunciación, a aquello que hoy llamamos producción social del sentido (Verón, 2004). Y esta fue la bandera que tomaron una buena parte de los intelectuales europeos, en un arco que cubrió desde la filosofía y las ciencias humanas hasta la arquitectura y la plástica. Estas últimas eran las referencias de proyectistas como el suizo Max Bill y el alemán Otl Aicher, quienes habían sufrido la expansión del nacional socialismo.

\section{La sospecha del lenguaje}

La respuesta era sencilla pero problemática. Parecía no caber duda acerca del nivel de mentiras que se habían desplegado y de la responsabilidad de la prensa en aquel momento. La prensa, los periodistas y quienes habían legitimado la estigmatización que llevó al genocidio eran una suerte de operadores culturales de grandes dispositivos ideológicos, y la propaganda resultaba su mayor expresión. Se le acusaba precisamente de esto: tergiversar la realidad, parcializar el mundo, mentir, engañar y trabajar sin ninguna clase de ética. De alguna forma, se recuperaban las advertencias que ya Karl Kraus había lanzado casi veinte años antes respecto del nefasto papel de la prensa en la Primera Guerra Mundial: los llamados incendiarios de los Estados europeos a su población para asistir a una guerra absurda, sanguinaria y devastadora, y la irresponsabilidad frente a la masacre. La prensa que operaba con el lenguaje no podía ser ingenua. Sabía que éste (el lenguaje) ya había sido sospechado de su supuesta capacidad representativa del mundo, y jaqueado en consecuencia luego de la experiencia de las vanguardias estéticas, y que solo le quedaba -como lugar de fortaleza- el plano retórico, los artificios de la persuasión. Indudablemente, las vanguardias ya para los años '10 y '20 del siglo XX habían demostrado que los lenguajes no podían representar al mundo, no podían organizar una experiencia sensible vinculada al plano referencial, que antes que transparencia lo que resultaba evidente era su opacidad. Una nueva misión para el arte -esperanzadora por cierto- se desprendía de esta triste comprobación: lo artístico debía dar cuenta de esa insuperable opacidad instalada entre el hombre y el mundo. Desde ese momento, desentrañar el mundo era comenzar a preguntarse por los lenguajes de su presentación y señalar la abierta imposibilidad de representaciones totales, de visiones generales, de explicaciones absolutas. Si esto era así en el plano artístico, en el terreno de la información -como bien estaba convencido Kraus (Casullo, Foster y Kaufman, 1999) la responsabilidad sobre el lenguaje y el decir era enorme. Y parte de la anestesiada percepción europea sobre la guerra -ya claramente presente en la primera contienda mundial- era producto de la creciente instrumentalización del lenguaje y de la renuncia de sus operadores a preguntarse qué se hacía con las palabras: a quienes se servía, qué intereses se estaban sosteniendo, qué responsabilidades les cabía (Casullo, Foster y Kaufman, 1999).

A estos antecedentes, vinculados a la experiencia de las vanguardias, que sospechan sobre la correspondencia lineal entre lenguaje y mundo cabe sumarles los intentos deliberados por la recuperación de un lenguaje universal, sin rasgos estilísticos epocales, sin anclajes locales, privados de una asociación con una clase social en particular. Hacia allí se encamina, precisamente, la mayoría de las vanguardias constructivas que, una vez que asumen la decadencia del mundo burgués de la Belle Ėpoque y la crisis representacional del lenguaje, asumen como desafío la construcción de un nuevo rol para el arte: la búsqueda de una síntesis mayor donde lo estético devenga uno de los caminos de la construcción de un nuevo mundo (Crispiani, 2004). 
Antecedentes que, precisamente, van a recalar en Bauhaus en particular a partir de la llegada del Neoplasticismo y el Constructivismo soviético. En ese contexto, las figuras de László Moholy-Nagy y Herbert Bayer son centrales (VV.AA., Revista Controspazio, 1971). El primero por haber sentado las bases del proyecto vertebral del nuevo arte: la facultad de promover una "nueva visión" (Moholy-Nagy, 1957) del mundo y de su experiencia. Al segundo, además de haber sido uno de los miembros más prolíficos de la escuela, se le deben toda una serie de experimentos tipográficos que redundarán en la propuesta por abolir la distinción entre mayúsculas y minúsculas, intentando equiparar el leguaje escrito al hablado. Por primera vez, las propuestas del Diseño tendrían un correlato con los descubrimientos científicos sobre lo óptico, la formación de imágenes en la mente, los estudios sobre el planismo, la composición y la percepción visual del movimiento. ${ }^{2}$ El programa conjugaba el imperativo científico tecnológico con una finalidad social. Así, la legibilidad, la liquidación de inflexiones estilísticas, regionales y las connotaciones de clase, permitían el despliegue de modalidades de producción de texto y de lectura que fueran masivas, entendiendo que la masividad suponía antes que nada democracia en el acceso.

De esta forma, los intentos iban encaminándose hacia el desarrollo de un repertorio de objetos de Diseño, de prácticas de Diseño que tenían como horizonte la posibilidad de establecer un usuario universal. Un ser humano al que se lo había estudiado para poder responder a sus necesidades vitales, estableciendo una tipología de usos y funciones. De este intento, prolífico por cierto, surge el imperativo de síntesis, simplicidad, funcionalidad y transparencia (Devalle, 2009).

\section{Comunicación e ideología en la posguerra}

Precisamente, si se trataba de que los objetos y los textos fueran accesibles debían eliminarse los obstáculos que impedían comprender su usabilidad. Este postulado, en el terreno de la comunicación, sentó las bases para el desarrollo de una forma de comprensión de los hechos del sentido teñidos de valores y juicios sobre el buen y mal uso -en un sentido técnico y también político- de la materia del lenguaje. Hacia allí precisamente apuntan gran parte de las acusaciones que luego de la Segunda Guerra se disparan contra la propaganda en la medida en que ésta es vista como un mecanismo productor de fantasías, constructor de mentiras y opacidades o, de otra forma, como el gran obstáculo para acceder a una conciencia plena de los hechos y tomar una distancia crítica sobre los acontecimientos.

Esta caracterización, propia de una época que había quedado atónita frente a lo sucedido en la Segunda Guerra, es también producto de las corrientes vinculadas al marxismo en tanto pensamiento social, en la medida en que recuperan el clásico concepto de "conciencia", "falsa conciencia" y "alienación", por solo citar a las más recurrentes. Desde aquí, una buena porción de las reflexiones marxistas que retoman el trauma del Holocausto y se preguntan por sus condiciones de posibilidad, no dejan de vertebrar sus argumentos en torno de la categoría "alienación" en algunos casos, "manipulación" en otros o, en palabras del mismo Maldonado, directamente "charla" como una figura discursiva en abierta oposición con el alto propósito de la comunicación social. Efectivamente, en un artículo ya clásico sobre los propósitos de la comunicación visual (Maldonado, 1953), éste afirmaba que lo que diferenciaría una de otra era, además de sus intenciones, sus procedimientos. Así, mientras la comunicación suponía "la 
explosión del lenguaje", la charla repitía núcleos pseudo-comunicativos, pseudo-significativos, como consigna, núcleos vacíos de una expresión dramática: “(...) únicamente los estados explosivos, es decir, los estados de animación intensa provocados por el advenimiento de imágenes nuevas, pueden favorecer la vida comunicativa" (Maldonado, 1953, p. 22).

¿Qué interés tiene esta diferenciación? Centralmente, la posibilidad de establecer visiones abiertas y cerradas del mundo, instancias de transparencia y opacidad, de conexión real con el mundo o de su mistificación. Y allí es hacia donde va la reflexión de Maldonado al considerar la charla como modus operandi de la ideología.

Tras haber realizado un análisis histórico sobre el modo en que el pensamiento moderno generó una conciencia crítica de la relación entre hombre y mundo, este autor-que se caracteriza, entre otras cuestiones por iniciar una filosofía de la tecnología moderna- anticipa de algún modo uno de los debates centrales en la constitución del Diseño Gráfico como comunicación visual. Esto es, la relación ética (y por cierto metafísica) entre verdad y discurso, la responsabilidad social de los comunicadores.

El especialista en comunicación visual sabe que es responsable (o cómplice) de todo lo que ocurre con los ojos del hombre común. De todo lo que habita en ellos: fantasmas, hipogrifos o certidumbres. Ninguno llega a ignorar que su misión es fabricar ideologías o participar activamente de su demolición (Maldonado, 1953, p. 24).

La comprobación de que, efectivamente, en el terreno del arte la significación cumple un papel sumamente importante lleva a considerarlo como un laboratorio privilegiado de los sentidos inscriptos en el mundo, y por lo tanto el impulso del verdadero hecho comunicativo, en la versión que aquí se presenta de la comunicación. El arte, particularmente las vanguardias constructivas y el Arte Concreto donde él mismo participaba, son el camino para la creación de una nueva conciencia de la praxis social.

Este tipo de diagnósticos, se vinculan estrechamente con los presupuestos marxistas sobre las formas ideológicas y sus modalidades de presentación. La ideología es entonces, no solo un conjunto de falsas ideas respecto de la situación del hombre en el mundo -particularmente la situación de clase que hace que el proletario adopte la forma del pensamiento y los valores burgueses- sino también una forma de construcción de las prácticas de diferenciación que implican desigualdad (antesala de la justificación de la discriminación y del racismo). Una ideología que construyó como antagónicas las diferencias entre pueblos y razas -propia del conjunto de los nacionalismos- y dejó de lado a la verdadera contradicción social que se instala no ya entre pueblos (hermanos) sino entre clases: entre quienes detentan los medios de producción y quienes se encuentran privados de ello. Desde aquí, la misión del arte en la visión de los artistas que adscribían al marxismo -tal el caso de Tomás Maldonado y de los artistas concretos en general- es la de transformarse en vehículo de una nueva conciencia. De ahí también la importancia del concepto de "nueva visión" elaborado por Moholy-Nagy pero recuperado por todas las vanguardias constructivas, dado su potencial de síntesis.

Las razones de su importancia descansan en que el término alude -por lo menos- a un doble propósito. El arte debía permitir ver el mundo con otros ojos - ver lo que no podía ser visto con las viejas categorías del arte representativo- y poder verlo para transformarlo en un senti- 
do técnico social: operar sobre el mundo, intervenirlo. De alguna forma se presuponía que al cambiar la visión sobre el mundo se iba a develar la falsedad de la configuración ideológica e impulsar un vínculo real y verdadero del hombre con los hombres y con el mundo en general. Este tipo de presupuestos también descansaba en una sobre valoración de las prácticas científicas como camino hacia la verdad y hacia lo real. De ahí que el conjunto de las artes modernas de corte constructivo, en particular el Arte Concreto, considerasen el proyecto de síntesis de las artes como uno de los objetivos a perseguir y a la matemática como una de sus posibilidades. En este sentido se orienta, a modo de ejemplo, la metodología de las series plásticas del artista suizo Max Bill (Perazzo, 1983).

La "nueva visión" es quizás, entonces, el significante que permite comprender las características y misiones asignadas al arte moderno y a su despliegue (dialéctico) cuyo norte lo constituía un proyecto real de intervención en el mundo producto de la síntesis de las artes y la comunión de artistas con técnicos y hombres de la ciencia. Nueva Visión fue así un programa artísticopolítico, un proyecto académico y como corolario el nombre de la revista argentina donde se empiezan a anudar los contenidos de lo que luego -y veinte años después- se conocería como "proyectualidad". Lo proyectual como concepto, podemos adelantarlo, es fruto de esta experiencia de vanguardia que en los años '50 revisó las bases conceptuales del arte y la arquitectura modernas y no encontrando una respuesta acorde a los desafíos del mundo de la posguerra, corrió su mirada hacia la técnica, los desarrollos científicos, la necesaria vinculación con la industria y la permanente vocación de mejoramiento del mundo. Siendo este último, quizás, uno de los pocos principios que se conservarían indemnes luego de veinte años.

Del conjunto de estas prácticas (intelectuales, políticas, artísticas) que articulan la crisis de los lenguajes representacionales, un proyecto refundacional para el arte -particularmente visible en las vanguardias constructivas con su búsqueda de una síntesis de las artes-, la confianza desplegada en torno a la ciencia y la tecnología como plataformas de acceso al mejoramiento de las condiciones de vida, y el marxismo como filosofía materialista que vincula la conciencia, el leguaje y la praxis social, de ese conjunto surgirá una nueva modalidad de comprensión de la comunicación acorde con las urgencias de la segunda posguerra.

\section{Comunicación y lenguaje en el mundo proyectual}

Hace apenas dos años, Joan Costa -referente indiscutido del Diseño Gráfico- dictó una conferencia en el marco de la apertura del curso académico 2008-2009 en la Universidad Abat Oliba, reproducida por el Foro Alfa (Foroalfa.org, 2010). Allí Costa, entre otras cuestiones, afirmaba que la comunicación y la información se habían transformado radicalmente desde hace ya sesenta años, a partir de los acontecimientos abajo descriptos. En orden de importancia mencionaba:

En el ámbito científico, en 1948 Norbert Wiener publicaba la obra capital $C y$ bernetics: control and communication in the animal and the machine. Al mismo tiempo, Warren Weaver publicó su célebre artículo titulado "Ciencia y Complejidad", y Claude Shannon, alumno de Wiener, publicaba The mathematical Theory of Communication. Shannon dio al subjetivo concepto de información 
una expresión matemática, una magnitud mensurable universal, que puede aplicarse a una lengua, una música, una organización o al patrimonio genético de un organismo. Esta obra sintetizó los trabajos dispersos que se remontaban al inicio de la era de las comunicaciones (Graham Bell, Hartley, Einstein, Zobel, Szilard, Boltzmann) y facilitó una medida del valor de la comunicación, punto esencial que determinaría todo el desarrollo de lo que hoy llamamos ciencia de la comunicación o de la información. En el campo tecnológico, finalmente, la aparición de estos dos libros y todo lo que ellos aportaban cristalizó con uno de sus resultados tecnológicos más determinantes. En 1948, las primeras máquinas de manipular información (data processing) eran comercializadas por IBM con el término de computer machines, fruto de lo que Alan Turing había formulado con su teoría de la computación basada en el código binario (Foroalfa.org, 2010).

La cita es útil en la medida en que en el planteo de Costa se adivina el convencimiento de la vigencia explicativa de los modelos comunicacionales propios del contexto de la segunda posguerra en el ámbito proyectual. Dicho en otros términos, al recuperarlos como referencias que permiten comprender al día de hoy el funcionamiento de la comunicación, Costa los consolida en la actualidad como marco teórico de la comunicación visual. En este sentido, y más allá de esta conferencia, la presencia en el mundo del Diseño Gráfico de términos como "eficacia del mensaje", "correcta comprensión", "ruido", "desfasaje" en las explicaciones sobre la implementación de un programa -a modo de ejemplo- o el desarrollo de un proyecto, ilustran de forma contundente el hecho de que la comunicación continúe siendo comprendida como transmisión de información. Esta constatación resulta aún más sorprendente cuando se revisa históricamente el momento en que aparece configurada como referencia en el ámbito del Diseño. Efectivamente, la misma posee un origen preciso que se remonta a las enseñanzas de la Hochschule für Gestaltung de la ciudad de Ulm, particularmente cuando allí se opera el giro cientificista de la mano de Hans Gugelot, Otl Aicher y Tomás Maldonado, quienes impulsan -particularmente Maldonado- la formación en cibernética, teoría de la información y matemática como disciplinas pilares a partir de las cuales se podía construir teórica y metodológicamente las particularidades de la comunicación en el ámbito de la proyectualidad.

Esta vinculación de alguna manera quedó tramada y consagrada con un gesto no menor, que consistió en la invitación, a mediados de los años '50, de Norbert Wiener como Profesor externo, precisamente en el momento en el que la escuela revisaba sus programas de estudio y se volcaba hacia una comprensión del Diseño más vinculada a las ciencias, la técnica y la industria en desmedro de la faceta experimental que la había caracterizado bajo la dirección de Max Bill. En este giro, el rol de Tomás Maldonado y Otl Aicher -conviene recordarlo- fue central. Efectivamente, Maldonado en una carta a su amigo Jorge Grisetti ${ }^{3}$ fechada en 1957 afirmaba:

Max Bill se va definitivamente de Ulm la semana próxima. La prehistoria de nuestro Instituto ha terminado (...) Él quería un Bauhaus donde se enseñara a producir buenas formas. Estas buenas formas deberían ser producidas desde fuera de la industria por artistas puros e inspirados a los cuales la industria debía someterse (Crisipiani, 2004). ${ }^{4}$ 
Desde ese momento, la Escuela de Ulm asumió un perfil técnico social con fuerte énfasis en las metodologías del proyecto. Tal como referimos, se convocaron disciplinas y teóricos afines que podían contribuir a la consolidación de una perspectiva del Diseño directamente relacionado como factor de intervención en el mundo, en primer lugar: en la industria. En ese marco, la llegada de las teorías cibernéticas y matemáticas de la comunicación permitieron comprender bajo parámetros científicos las modalidades de producción, circulación y recepción de la información, pero también y paradójicamente, de alguna manera "encorsetaron" las posibilidades explicativas de la comunicación en el territorio de la proyectualidad al punto que, tal como se trasluce en el artículo de Joan Costa, parecieran al día de hoy ser las más adecuadas. Sin embargo, y a pesar de la fortaleza que posee siempre aquello que puede ser mensurable, al modelo referido se le pueden formular una serie de severos cuestionamientos, vinculados a un cierto reduccionismo en la comprensión de las prácticas comunicacionales. Sesenta años en el plano social y en la teoría es demasiado tiempo como para desconocer los aportes ulteriores y las posibles limitaciones de un modelo.

En este sentido, el gesto de énfasis científico, la vigencia del programa cibernético (innegable por otra parte en el ámbito de la informática) no puede disuadirnos de abrir la pregunta sobre qué otras perspectivas surgieron en estos últimos años ¿qué otras perspectivas se han habilitado? ¿Se ha cuestionado la expansión omnímoda de los postulados de Shannon, Wiener sobre todo fenómeno comunicativo?

El punto problemático es, de alguna manera, el haber establecido una comprensión de la comunicación en estrecho vínculo con la información, al punto que teóricamente los aportes de la segunda bien podrían explicar las innumerables manifestaciones de la primera. Efectivamente, hay una diferencia sustancial entre comunicar e informar; en este sentido, se podría sostener la información es una parte, importante por cierto, pero solo una porción de la comunicación que, como tal, engloba fenómenos mucho más amplios y complejos: la persuasión, las formas argumentativas, las formas en que se cristaliza el discurso social. Precisamente, el conjunto más amplio de fenómenos a los que refería Maldonado en el artículo citado párrafos más arriba sobre los problemas de la comunicación. Desde aquí, renunciar a su componente ideológico discursivo, a las formas sociales de producción del sentido, es explicar un fenómeno que bien se puede comprender en la asepsia del laboratorio pero que para poder abarcarlo en su complejidad es necesario verlo actuando (Arfuch, 1997).

En estas latitudes, particularmente en América Latina, el mundo proyectual ha sostenido -al día de hoy- la actualidad del modelo cibernético de la comunicación, desconociendo que como aporte teórico resulta sumamente útil en la medida en que se reconozca también el espectro de fenómenos que puede abarcar, sobre los que puede operar y ofrecer una adecuada explicación. Los mismos se circunscriben a la faceta informacional del Diseño, al Diseño de Información y por extensión a todos los circuitos donde la comunicación se vertebre en la correcta transmisión de información. En consecuencia, existen innumerables zonas de la comunicación visual abordada desde la misma proyectualidad, que no pueden ser explicados en su complejidad y que, desde la perspectiva informacional de la comunicación, se los califica como mensajes fallidos. Tal el caso de aquellos trabajos que presentan una adecuada resolución en términos proyectuales pero que no funcionan como propuestas una vez que se echan a rodar. Desconocer las razones de los "fracasos" comunicacionales en el territorio del Diseño es olvidar que la comunicación visual tiene -al día de hoy- tanto de proyectualidad como de comunicación 
social (Arfuch, 1997). Lo visual no deja de ser materia social y las representaciones históricas y colectivas no dejan de actuar al momento de la recepción, aún en el caso de piezas netamente referenciales sin aparente y explícito contenido social.

\section{Del código al discurso}

Aquello que se está señalando se vincula directamente con las reformulaciones que la misma comunicación sufrió una vez que se cuestionó la primacía del código. Por tal deben entenderse todas aquellas formulaciones que bajo el concepto de "sistema", "circulación", "codificación" y "decodificación", hicieron descansar el sentido final de los mensajes en el correcto o incorrecto manejo de la lengua/código. Así presentados, se podían mensurar claramente los mensajes bien o mal elaborados y determinar las razones de su éxito o de su fracaso. Esta perspectiva fue elaborada en primer lugar y dentro de la lingüística moderna por Ferdinand de Saussure (Saussure, 1916) pero en realidad no se detuvo en una formulación semio-lingüística sino que fue retomada -como ya se señaló- por las teorías de los sistemas y las formulaciones matemáticas del proceso de transmisión de información. En el plano de los usos del lenguaje propiamiento dicho, fue desarrollada en detalle por los enfoques funcionalistas de la comunicación (Jakobson, 1975). Sin embargo, y tal como se afirmó, esta perspectiva dejaba innumerables hechos de la comunicación sin una sólida explicación. Es así como dentro de la misma lingüística francesa comienzan los cuestionamientos que apuntaron, precisamente, a señalar los vacíos teóricos y los obstáculos que se presentaban si se suscribía sin más tanto al modelo saussureano -articulado en torno a la primacía del signo lingüístico- como también el modelo funcionalista, vertebrado sobre la idea de función comunicativa. Esta serie de observaciones sobre las limitaciones del modo en que la lingüística moderna había concebido y construido su objeto de estudio se formalizan con una serie de trabajos elaborados por Émile Benveniste en los años '60 que darían el puntapié inicial para lo que luego se conocería como Teoría de la Enunciación (Benveniste, 1989). A partir de esta corriente se busca recuperar la presencia del sujeto (en términos antropo-filosóficos) en el lenguaje (Stegmayer y Slipak, 2009). Las marcaciones de la "voz", las intencionalidades del discurso, los matices y modalizaciones en el hablar son el objeto privilegiado de esta perspectiva que se corona con el desarrollo del Análisis del Discurso como metodología de trabajo. Desde aquí: ¿qué elementos aporta para repensar la comunicación humana en un sentido amplio y la comunicación visual como un fenómeno más específico y singular? En primer lugar, el poder dar cuenta del fenómeno del sentido como construcción social. Y aquí la figura de Roland Barthes es señera pues resulta un autor pionero en su crítica a las perspectivas vinculadas al lenguaje como sistema, y quien tempranamente comienza a preguntarse por los otros sentidos articulados en los mensajes. El concepto de connotación -un término clásico dentro de la Semiología- es una verdadera llave que impulsa el interrogante sobre la ideología, del discurso como ideología y de esta última no ya como un conjunto de ideas sistematizadas en torno a un tema y la perspectiva de un sujeto, sino antes bien como un conjunto cristalizado de prácticas sociales articuladas a partir de la "naturalización" de una determinada mirada sobre un fenómeno. De esta forma, ideológico es el sentido de las prácticas sociales y no las ideas sobre una temática.

A la crisis de la omnipresencia del signo y del código se le suma el resquebrajamiento del concepto 
de "mensaje" como unidad de la comunicación. En su reemplazo, la noción de enunciado y de discurso resultan más pertinentes en la medida en que permiten dar cuenta de la relación entre contexto de producción, contexto de recepción y configuración de los enunciados. En ellos, efectivamente, aparecen las marcaciones espacio temporales, los modos del decir y el posicionamiento del sujeto que habla (el yo) y la figura del destinatario (el tú) de la comunicación discursiva.

Finalmente, la llegada de noción de texto también vinculada al concepto de discurso permite una articulación sumamente interesante pues ancla a la producción de sentido en una determinada materialidad y habilita una comprensión más acabada de los contextos de interpretación, entre "lo que el autor propone y lo que el lector dispone" (Eco, 1991). La noción de texto, por lo menos en el sentido en que Eco la trabaja, posee además un enorme potencial pues desarticula su comprensión como entidad homogénea por fuera de los "destinos" a los que tanto el autor como el lector condenan. De esta forma, no hay un texto, sino innumerables textos en su apariencia unitaria. En este umbral también se ubica la potencialidad del concepto de hipertexto con el emblemático trabajo de Barthes en S/Z (Barthes, 1971) como una de las tantas referencias clásicas.

Es a partir de este conjunto de reformulaciones que el trabajo sobre las formas de producción, circulación y recepción del material textual y discursivo cierra un ciclo de problematización semiótico-social y permite dilucidar la complejidad de los mecanismos de configuración del sentido social, que reconocen diversos lenguajes, soportes y formas de materialización. En este orden, ingresa de un modo por cierto tardío la reflexión en torno a la imagen.

\section{De lo icónico a lo visual}

En lo relativo a la cuestión de la imagen desde el punto de vista de la teoría de los signos, los aportes más sustantivos y basales fueron formulados en la vasta y compleja obra de Charles Sanders Peirce, particularmente sus Collected Papers editados tardíamente (Peirce, 1935-1958). A través de sus escritos se anticipa una mirada absolutamente novedosa que entiende que -a contrapelo de las corrientes positivistas contemporáneas- todo se encuentra mediados por signos y, en definitiva, que todo es signo. De allí que la imagen también lo sea. De esta forma, lo que la lingüística francesa había dejado entre paréntesis ingresa de modo abierto al terreno de la problematización de los lenguajes. Efectivamente: ¿es la imagen un signo? ¿constituyen las imágenes un código? ¿pueden ser consideradas un lenguaje? (Fiorini y Schilman, 2009). Este tipo de formulaciones, propias de la Europa continental entre los años ' 60 y '70 se resolverán una vez que se abandone definitivamente el modelo saussureano como referencia central a la hora de explicar la complejidad de la significación en materia visual.

El proyecto de la semiótica, por fuera del mundo anglosajón, encuentra en Umberto Eco (Eco, 1991) y en Eliseo Verón (Verón, 2004) ${ }^{5}$ dos baluartes que impulsan una comprensión de los procesos de producción de sentido más allá de la pertinencia del modelo lingüístico clásico. Así -y para los años '70- se cuestiona el rol de la imagen como referente natural del mundo y se postula la existencia de un nivel importante de convencionalismo en la percepción de la imagen como signo que representa por semejanza al objeto (Corti y Perelmiter, 2009). A partir de entonces, y ya entrados los años ' 80 , lo icónico dará paso a una reformulación más amplia donde comience a tallar lo visual como un marco de referencia que permita entender, además de las 
características macro de los procesos de producción de sentido, la singularidad que presenta lo visual como soporte, como dispositivo y como lenguaje, y abordarlo en su complejidad. Desde aquí, no es lo mismo entender lo visual como plataforma, como puesta en forma o como materia de configuración de sentido.

Justamente, los Estudios Visuales, nacidos a mediados de los años '90, pero con antecedentes importantes sobre los años ' 80 habilitan esta nueva problemática. La pregunta faro, formulada por Mitchell (Mitchell, 1985), resulta sumamente cautivante y vigente y podría reconstruirse del siguiente modo ¿cuánto de lo visual instituye lo social, cuánto de lo social instituye lo visual? En ella se cifra nuevamente, inquietudes respecto de la autonomía de los lenguajes, la consideración del lenguaje como dispositivo de comprensión de la imagen, la distinción entre lo icónico y lo visual, la crisis de la idea de imagen como representación, el esencialismo icónico y finalmente la idea de performance como presentación de y en el mundo. Las inflexiones de este debate recuerdan que nos encontramos frente a un desafío renovado, estos es: que debemos seguir pensando y problematizando la articulación entre la comunicación social y la visual.

En definitiva, recuperar un marco general donde la comunicación visual pueda ser releída acontece como una asignatura pendiente, aunque una parte muy interesante de trabajos teóricos han comenzado a problematizar este vínculo en los últimos años. En este sentido, los Estudios Visuales resultan una adecuada vía para rever los alcances y límites de los conceptos vertebrales del ámbito proyectual una vez que se los articula a un conjunto de reflexiones mayores sobre lo visual, los lenguajes y la presencia de lo social, no ya como "temática" sino como plataforma de generación de lo discursivo.

\section{Notas}

1. $n v$ fue fundada por Tomás Maldonado, Alfredo Hlito y Carlos A. Méndez Mosquera en 1951, y dirigida por el primero hasta 1954. El Comité de Redacción estuvo integrado por Borthagaray, Bullrich, Grisetti, Goldemberg, sumándose luego Baliero, Hlito, Bayley. Su último número, el 9, apareció en el año 1957.

2. Que habilitaría a la aparición de la psicología de la Gestalt.

3. Quien para entonces era director de la editorial Nueva Visión.

4. Carta de Tomás Maldonado a Jorge Grisetti, citada por Alejandro Crispiani en: Crisipiani, A. op, cit. pp. 40 y 44. La carta, del 20 de septiembre de 1957, se encuentra en el archivo de la Fundación Espigas. Buenos Aires.

5. Ver, entre otros: Verón, E. (2004). La semiosis social. México: Gedisa.

\section{Lista de Referencias Bibliográficas}

Arfuch, L. (1997). “El Diseño en la trama de la cultura. Desafíos contemporáneos” en Diseño y Comunicación. Teorías y enfoques críticos. Buenos Aires: Paidós.

Barthes, R. (1971). S/Z, Siglo XXI: Madrid.

Benveniste, E. (1989). Problemas de lingüistica general, Tomo I y II. México: Siglo XXI.

Casullo, N.; Forster, R.; Kaufman, A. (1999). Itinerarios de la modernidad. Buenos Aires: Eudeba. 
Corti, L. y Perelmiter, L. (2009). El problema de la iconicidad ¿naturaleza o convención? en Arfuch, L. y Devalle, V. (comps.). Visualidades sin fin. Imagen y diseño en la sociedad global. Buenos Aires: Prometeo.

Crispiani, A. (2004). Entre dos mundos: el largo viaje de la Buena Forma, revista Block número 6, Buenos Aires.

Devalle, V. (2009). La travesía de la forma. Emergencia y consolidación del Diseño Gráfico (19481984). Buenos Aires: Paidós.

Eco, U. (1991). El lector modelo en Lector in fabula. Barcelona: Lumen.

Fiorini, D. y Schilman, L. (2009). Apuntes sobre el sentido de la imagen en Arfuch, L. y Devalle,

V. (comps.). Visualidades sin fin. Imagen y diseño en la sociedad global. Buenos Aires: Prometeo.

Jakobson, R. (1975). Lingüística y poética en Ensayos de lingüística general. Barcelona: Seix Barral.

Maldonado, T. (1993). El diseño industrial reconsiderado. Barcelona: Gustavo Gili, pp. 61-63.

(1955). de Ulm. Primera etapa, revista $n v$ número 7, p. 7. Buenos Aires.

(1953). Problemas actuales de la comunicación, revista $n v$ número 4. Buenos Aires.

Mitchell, W. (1985). Iconology: Image, Text, Ideology. Chicago: University of Chicago Press.

Moholy-Nagy, L. (1957). La nueva visión. Buenos Aires: Editorial Nueva Visión.

Peirce, Ch. (1935-1958). Collected Papers. Cambridge: Harvard University Press.

Perazzo, N. (1983). El arte concreto en la Argentina. Buenos Aires: Ed. Gaglianone.

Saussure, F. (1916). Curso de lingüística general. Varias ediciones.

Stegmayer, M. y Slipak, D. (2009). Hacia una teoría de la lengua en uso: los aportes de Émile Benveniste en Arfuch, L. y Devalle, V. (Comps.). Visualidades sin fin. Imagen y diseño en la sociedad global. Buenos Aires: Prometeo.

Verón, E. (2004). La semiosis social. México: Gedisa.

VV.AA. (1971). Bauhaus. Madrid (traducción de artículos aparecidos en el número monográfico de la Revista Controspazio, 1970).

\section{Bibliografía}

Arfuch, L. (1997). "El Diseño en la trama de la cultura. Desafíos contemporáneos" en Diseño y Comunicación. Teorías y enfoques críticos. Buenos Aires: Paidós.

Bal, M. (2004). "El esencialismo visual y el objeto de los estudios visuales" en revista Estudios Visuales, número 3. Murcia: CENDEAC, diciembre.

Barthes, R. (1971). S/Z, Siglo XXI: Madrid.

Benveniste, E. (1989). Problemas de lingüística general, Tomo I y II. México: Siglo XXI.

Calabrese, O. [1985]. El lenguaje del arte. Barcelona: Editorial Paidós.

Casullo, N.; Forster, R.; Kaufman, A. (1999). Itinerarios de la modernidad. Buenos Aires: Eudeba.

Corti, L. y Perelmiter, L. (2009). El problema de la iconicidad ¿naturaleza o convención? en Arfuch, L. y Devalle, V. (comps.). Visualidades sin fin. Imagen y diseño en la sociedad global. Buenos Aires: Prometeo.

Crispiani, A. (2004). Entre dos mundos: el largo viaje de la Buena Forma, revista Block número 6, Buenos Aires.

Devalle, V. (2009). La travesía de la forma. Emergencia y consolidación del Diseño Gráfico (19481984). Buenos Aires: Paidós. 
Eco, U. (1991). El lector modelo en Lector in fabula. Barcelona: Lumen.

Fiorini, D. y Schilman, L. (2009). Apuntes sobre el sentido de la imagen en Arfuch, L. y Devalle, V. (comps.). Visualidades sin fin. Imagen y diseño en la sociedad global. Buenos Aires: Prometeo. Foucault, M. [1969]. La arqueología del saber. México: Siglo XXI.

[1966]. Las palabras y las cosas. Una arqueología de las ciencias humanas. México: Siglo XXI. Geertz, C. (1994). La interpretación de las culturas. Barcelona: Gedisa.

Gené, M. (2005). Un mundo feliz. Imágenes de los trabajadores en el primer peronismo 1946-1955. Buenos Aires: FCE.

Jakobson, R. (1975). Lingüística y poética en Ensayos de lingüística general. Barcelona: Seix Barral. Maldonado, T. (1993). El diseño industrial reconsiderado. Barcelona: Gustavo Gili, pp. 61-63.

(1955). de Ulm. Primera etapa, revista $n v$ número 7, p. 7. Buenos Aires.

(1953). Problemas actuales de la comunicación, revista $n v$ número 4. Buenos Aires.

Mitchell, W. (1985). Iconology: Image, Text, Ideology. Chicago: University of Chicago Press.

Mirzoeff, N. (1999). An Introduction to Visual Culture. London: Routledge.

Moholy-Nagy, L. (1957). La nueva visión. Buenos Aires: Editorial Nueva Visión.

Peirce, Ch. (1935-1958). Collected Papers. Cambridge: Harvard University Press.

Perazzo, N. (1983). El arte concreto en la Argentina. Buenos Aires: Ed. Gaglianone.

Saussure, F. (1916). Curso de lingüística general. Varias ediciones.

Stegmayer, M. y Slipak, D. (2009). Hacia una teoría de la lengua en uso: los aportes de Émile Benveniste en Arfuch, L. y Devalle, V. (Comps.). Visualidades sin fin. Imagen y diseño en la sociedad global. Buenos Aires: Prometeo.

Verón, E. (2004). La semiosis social. México: Gedisa.

Vilches, L. (1986). La lectura de la imagen. Barcelona: Editorial Paidós.

VV.AA. (1971). Bauhaus. Madrid (traducción de artículos aparecidos en el número monográfico de la Revista Controspazio, 1970).

\title{
Recursos Electrónicos
}

http://foroalfa.org/es/articulo/167/60_anos_de_comunicacion. Consultado marzo 2010.

\begin{abstract}
Summary: The article proposes an historical review on the relation between design, communication and language. The author starts with the artistic-political vanguards of principles of the Xxth century to reach the first modern tension between language and communication. On the other hand, the analysis of the Bauhaus allows to understand the relation between communication and design. After this first part, the text goes towards the communicational problems that appear in the immediate postwar period and the way in which design begins to assimilate conceptions of the cybernetics theory of the communication. In this point, the article reviews the advances in communicational concepts in the last decades that, sometimes collide with projects universe where the design is located.
\end{abstract}

Key words: communication - design - discipline - history - language. 
Resumo: $\mathrm{O}$ artigo propõe um percurso histórico sobre a relação problemática entre design, comunicação e linguagem. O ponto de partida é a consideração sobre as linguagens que fazem as vanguardias artístico-políticas de princípios do século XX para acceder a uma primeira tensão -moderna- entre linguagem e comunicação. Por outro lado, a analise do desenvolvido em Bauhaus permite compreender a relação entre comunicação e design. Depois, o texto avança até os problemas comunicacionais que se apresentam na imediata posguerra e a maneira em que o design comenza a assimilar concepções que vêm da teoria cibernética da comunicação. Neste ponto, o artigo repassa os avanços nas comunicações nas últimas décadas e que, em ocações, chocam com o univertso projetual onde se ubica o design.

Palavras chave: comunicação - disciplina - design - história - linguagem. 